INDONESIAN HEALTH ISSUE

\title{
Efektivitas Aroma Terapi Lavender Untuk Mengurangi Kecemasan Saat Pemasangan IUD Pada Akseptor KB IUD
}

\author{
Eka Falentina Tarigan ${ }^{1}$, Srilina Br.Pinem ${ }^{2}$, Andriani ${ }^{3}$, Median Jelita Lahagu ${ }^{4}$, \\ Nirmala Devi ${ }^{5}$ \\ 1-6 STIKes Mitra Husada Medan \\ Email korespondensi: ekafalentina5@gmail.com \\ No HP: 082164777687
}

\begin{tabular}{l}
\hline ARTICLE INFO \\
Received \\
01 Januari 2022 \\
Accepted \\
14 Februari 2022 \\
Published \\
19 Februari 2022 \\
\hline
\end{tabular}

Kata Kunci:

Aromaterapi;

Lavender;

Kecemasan;

Pemasangan IUD

Keywords:

Aromatherapy;

Lavender

Anxiety;

IUD Insertion

\begin{abstract}
ABSTRAK
Latar Belakang:Berdasarkan data BKKBN, Hasil prevalensi KB di Indonesia berdasarkan Survei Pemantauan Pasangan Usia Subur tahun 2013 mencapai angka 65,4\% dengan metode KB yang IUD (4,7\%). Hasil tersebut sedikit menurun jika dibandingkan dengan hasil survei tahun 2009-2011 prevalensi KB cenderung tetap pada kisaran angka 67,5\%. Tujuan dari penelitian ini Untuk mengetahui "Efektivitas Aroma Terapi Lavender untuk Mengurangi Kecemasan Pemasangan IUD Pada Akseptor KB IUD di Rumah Bersalin Kasih Ibu Sejati Kota Medan Tahun 2021." Penelitian ini telah di laksanakan di Rumah Bersalin Kasih Ibu Sejati Kota Medan. Waktu penelitian ini berlangsung dari bulan April 2021 - September 2021.Metode: Jenis penelitian penelitian quasi eksperimen kuantitatif dengan rancangan posttest nonequivalent control group yaitu suatu penelitian yang dilakukan dengan memberikan sebuah perlakuan untuk mengetahui gejala atau pengaruh yang timbul akibat perlakuan yang diberikan untuk membandingkan hasil aromaterapi lavender dengan suatu kelompok kontrol yang serupa dalam mempengaruhi kecemasan akseptor KB IUD. Pada penelitian ini akan dilakukan post-test dengan menggunakan pengukuran kecemasan untuk membandingkan yang diberi perlakuan dan tidak diberi perlakuan Hasil: Untuk menguji keefektivan aroma terapi lavender dilakukan uji paired sample t test didapatkan hasil untuk $P$ Value $=0,000$ artinya $p<0,05$, menyatakan bahwa Aroma Terapi Lavender Efektiv Untuk Mengurangi Kecemasan Pemasangan IUD Pada Akseptor KB IUD di Rumah Bersalin Kasih Ibu Sejati Kota Medan Tahun 2021.Kesimpulan: Disarankan bagi petugas kesehatan untuk memberikan aromaterapi lavender saat pemasangan IUD untuk mengurangi kecemasan akseptor KB IUD.
\end{abstract}


quantitative quasi-experimental research with a posttest nonequivalent control group design, namely a study conducted by giving a treatment to determine the symptoms or effects that arise as a result of the treatment given to compare the results of aromatherapy lavender with a control group that was similar in influencing the anxiety of IUD KB acceptors. In this study, a post-test was carried out using anxiety measurements to compare those who were treated and not treated. Results: To test the effectiveness of lavender aromatherapy, a paired sample $t$ test was carried out, the results obtained for $P$ Value $=0.000$, meaning $p<0.05$, stating that Lavender Aromatherapy is Effective for Reducing Anxiety of IUD Insertion in IUD KB Acceptors at the Kasih Ibu Sejati Maternity Home in Medan City in 2021. Conclusion: It is recommended for health workers to provide lavender aromatherapy during IUD insertion to reduce the anxiety of IUD KB acceptors. 


\section{PENDAHULUAN}

Masih tingginya laju pertumbuhan penduduk Indonesia merupakan permasalahan yang besar, dan diperlukan perhatian dan penanganan yang sungguh-sungguh dari semua pihak baik masyarakat maupun pemerintah.Laju pertumbuhan penduduk yang tidak dapat dikendalikan mengakibatkan banyak dampak terhadap penduduk yaitu menderita kekurangan makanan dan gizi sehingga mengakibatkan tingkat kesehatan memburuk, mempunyai pendidikan yang rendah, dan banyak penduduk yang pengangguran (BKKBN, 2015).

Menurut World Health Organization (WHO), banyak wanita yang menderita dan meninggal karena masalah kesehatan yang serius selama kehamilan dan persalinan. Pada 2015, diperkirakan 303.000 wanita di seluruh dunia meninggal karena sebab infeksi .Hampir semua kematian ini (99\%) terjadi di Negara berpenghasilan rendah dan menengah (LMIC), dengan hamper dua pertiga (64\%) terjadi di Wilayah Afrika WHO(WHO, 2018).

Data WHO menunjukkan bahwa pengguna alat kontrasepsi Implant di seluruh IUD $15,2 \%$. Pada saat ini diperkirakan memakai IUD/AKDR, 30\% terdapat di Cina, 13\% di Eropa, 5\% di Amerika Serikat, 6,7\% di negara-negara berkemabang lainnya. Dinegara Asseciation Of Southeast Asian Natins (ASEAN) sendiri, Indonesia memiliki jumlah penduduk terdapat pertama dengan jumlah penduduk sekitar 255 juta jiwa atau sekitar 3,5\% dari keseluruhan jumlah penduduk dunia, di susul oleh negara Filipina memiliki sekitar 102,5 juta jumlah penduduk. Serta negara terdapat ketiga adalah negara Vietnam dengan 90,7 juta jiwa (Safrina 2012).

Tingkat pencapaian pelayanan Keluarga Berencana dapat dilihat dari Cakupan Pasangan Usia Subur (PUS/ pasangan suami istri, istri berusia 20 sampe dengan 49 tahun) yang sedang menggunakan alat/metode kontrasepsi (KB Aktif) serta metode kontrasepsi yang paling banyak digunakan Pasangan Usia Subur (PUS) (Profil Kesehatan SUMUT, 2016).

Hasil prevalensi KB di Indonesia berdasarkan Survei Pemantauan Pasangan Usia Subur tahun 2013 mencapai angka 65,4\% dengan metode KB yang IUD (4,7\%). Hasil tersebut sedikit menurun jika dibandingkan dengan hasil survei tahun 20092011 prevalensi KB cenderung tetap pada kisaran angka 67,5\% (BKKBN, 2013).

Peserta KB aktif di Sumatera Utara yang berhasil dibina sebanyak 2.326.172 pasangan $(64,64 \%)$ dari seluruh pasangan usia subur (PUS). Realisasi peserta KB aktif yang menggunakan kontrasepsi AKDR/IUD 153.627 peserta (10,22\%), (BKKBN Sumut, 2011).

Alat Kontrasepsi Dalam Rahim atau Intra Uterine Device (IUD) Merupakan salah satu alat kontrasepsi yang baik buat kaum wanita. Alat ini sangat efektif dan tidak perlu diingat setiap hari seperti halnya KB Pil, dan KB Suntik setiap bulan atau tiap tiga bulan. Bagi ibu yang menyusui, IUD tidak mempengaruhi ASI, kelancaran ataupun kadar Air Susu Ibu (ASI). Namun terdapat beberapa wanita yang ternyata belum dapat menggunakan sarana kontrasepsi ini, dengan alasan mengalami kecemasan saat dilakukan pemasangan IUD akibat takut jika merasa sakit karena itu setiap calon akseptor KB metode IUD perlu memperoleh informasi yang lengkap tentang metode pemasangan IUD, manfaat pemakaian kontrasepsi IUD, kategori wanita yang cocok menggunakan IUD, manfaat pemakaian kontrasepsi IUD, kontra indikasi pemakaian IUD dan kapan harus kontrol lagi (Kemenkes RI, 2015).

Salah satu cara nonfarmakologi menurunkan tingkat kecemasan pada seseorang saat dilakukan pemasangan IUD yaitu dengan relaksasi. Relaksasi merupakan salah satu bagian dari terapi nonfarmakologis, yaitu Complementery And 
Alternative Therapies (CATs) yang di kelompokkan dalam Mind-body and spiritual terapies. Terapi relaksasi banyak digunakan dalam menangani nyeri dan kecemasan karena tidak memiliki efek samping, mudah dalam pelaksanaannya, tidak memerlukan waktu yang banyak serta relatif murah. Banyak jenis relaksasi yang digunakan sebagai terapi nonfarmakologis antara lain terapi relaksasi Musik, relaksasi Modifikasi dan relaksasi dengan Aromaterapi (Solehati \& Kosasih, 2015).

Aromaterapi adalah metode yang menggunakan minyak essensial untuk meningkatkan kesehatan fisik, emosi dan spiritual. Efek lainnya adalah menurunkan nyeri dan kecemasan. Minyak essensial atau minyak astiri yang bersifat menurunkan atau menghilangka nyeri salah satunya adalah lavender. (Solehati \& Kosasih, 2015). Lavender ini akan meningkatkan gelombang alfa dalam otak dan gelombang inilah yang akan membuat tubuh menjadi rileks dan akan mengurangi rasa nyeri yang di rasakan (Sharma, 2009).

Aromaterapi juga dapat menurunkan tingkat nyeri pada seseorang yang mengalami kecemasan saat dilakukan pemasangan IUD,sebab aromaterapi juga dapat memberikan efek stimulasi, memberikan sensasi yang menenangkan diri, otak, keseimbangan, stress yang dirasakan, relaksasi pada pikiran dan fisik pada tubuh sehingga efek inilah yang dapat menurunkan nyeri pada seseorang. Jika pikiran terasa tenang dan rileks maka akan tercipta suasana yang nyaman, dan kecemasan pun dapat berkurang (Najmi, 2011).

Berdasarkan data yang didapat dari hasil survei di Rumah Bersalin Kasih lbu Sejati Kota Medan, bahwa ada sebanyak 5 dari 10 orang ibu mengatakan cemas saat dilakukan pemasangan IUD yang menyebabkan rendahnya pengguna KB IUD.

Dari uraian diatas penulis tertarik untuk melakukan penelitian tentang "Efektivitas Aroma Terapi Lavender untuk Mengurangi Kecemasan Pemasangan IUD Pada Akseptor KB IUD di Rumah Bersalin Kasih Ibu Sejati Kota Medan Tahun 2021."

\section{METODE PENELITIAN}

Penelitian ini menggunakan metode quasi eksperimen kuantitatif dengan rancangan posttest nonequivalent control group yaitu suatu penelitian dengan memberikan sebuah perlakuan untuk mengetahui gejala atau pengaruh yang timbul akibat perlakuan yang diberikan untuk membandingkan hasil aromaterapi lavender dengan suatu control yang serupa dalam mempengaruhi kecemasan akseptor KB IUD, Penelitian dilaksanakan di Rumah Bersalin Kasih Ibu Sejati Kota Medan dan pelaksanaanya April 2021- September 2021. Populasi 36 orang, dengan tehnik pengabilan sampel total sampling, kuesioner pengukuran kecemasan dengan Skala $H R S-A$, analisis data paired sample $t$ test, dan penyajian data univariat dan bivariat. 


\section{HASIL PENELITIAN}

a. Analisis Univariat

1) Berdasarkan table 1 mayoritas tingkat kecemasan pada responden pada kelompok control prestest dalam kategori berat yaitu 8 responden (50\%) dan pada saat posttest juga dilakukan pengukuran kecemasan pada kelompok control mayoritas responden juga berada pada kategori kecemasan berat yaitu 11 orang 2) $(42,3 \%)$, dapat dilihat pada tabel sebagai berikut :

Tabel 1 Distribusi Frekuensi Tingkat Kecemasan Akseptor KB IUD Pada Kelompok Kontrol di Rumah Bersalin Kasih Ibu Sejati Kota Medan Tahun 2021

\begin{tabular}{|c|c|c|c|c|}
\hline Variabel & $\begin{array}{l}\text { F } \\
\text { Persentase(\%) }\end{array}$ & Variabel & $\mathbf{F}$ & $\begin{array}{l}\text { Persentase } \\
(\%)\end{array}$ \\
\hline Kecemasan Pretest & & Kecemasan Posttest & & \\
\hline 1. Tidak ada cemas & 3,8 & Tidak ada cemas & 0 & 0 \\
\hline 2.Kecemasan ringan & 15,4 & Kecemasan Ringan & 0 & 0 \\
\hline 3.Kecemasan sedang & 30,8 & Kecemasan sedang & 2 & 7,7 \\
\hline 4. Kecemasan berat & 50,0 & Kecemasan berat & 11 & 42,3 \\
\hline 5. Panik & 0 & Panik & 0 & 0 \\
\hline Total & 100 & 100 & 13 & 100 \\
\hline
\end{tabular}

3) Berdasarkan table 4.2 mayoritas tingkat kecemasan pada responden pada kelompok control prestest dalam kategori berat yaitu 8 responden (50\%) dan pada saat posttest juga dilakukan pengukuran kecemasan pada kelompok control mayoritas responden juga berada pada kategori kecemasan berat yaitu 11 orang $(42,3 \%)$, dapat dilihat pada tabel sebagai berikut :

Tabel 2 Distribusi Frekuensi Tingkat Kecemasan Akseptor KB IUD Pada Kelompok Intervensi di Rumah Bersalin Kasih Ibu Sejati Kota Medan Tahun 2021

\begin{tabular}{cccllc}
\hline No $\quad$ Variabel & $\begin{array}{l}\text { F } \\
(\%)\end{array}$ & Presentase & Variabel & F & $\begin{array}{l}\text { Persentase } \\
(\%)\end{array}$ \\
\hline Kecemasan Pretest & & & Kecemasan Posttest & & \\
1. Tidak ada cemas & 0 & 0 & Tidak ada cemas & 1 & 3,8 \\
2. Kecemasan ringan & 1 & 3,8 & Kecemasan Ringan & 11 & 42,3 \\
3. Kecemasan sedang & 6 & 23,1 & Kecemasan sedang & 1 & 3,8 \\
4. Kecemasan berat & 6 & 23,1 & Kecemasan berat & 0 & 0 \\
5. Panik & 0 & 0 & Panik & 0 & 0 \\
\hline Total & 13 & 100 & 100 & 13 & 100 \\
\hline
\end{tabular}

\section{b. Analisis Bivariat}

Efektivitas Aroma Terapi Lavender Untuk Mengurangi Kecemasan Pemasangan IUD Pada Akseptor KB IUD Rumah Bersalin Kasih Ibu Sejati Kota Medan Tahun 2021. Penjelasan hasil uji simple paired $t$ Test sebelum dan setelah diberikan Aroma Terapi Lavender dapat dilihat pada tabel sebagai berikut :

Tabel 3 Efektivitas Aroma Terapi Lavender Untuk Mengurangi Kecemasan Pemasangan IUD Pada Akseptor KB IUD di Rumah Bersalin Kasih Ibu Sejati Kota Medan Tahun 2021

\begin{tabular}{lccl}
\hline Pengetahuan & $\mathrm{N}$ & $\mathrm{T}$ & Nilai $P$ \\
\hline Kelompok Kontrol & 26 & 12,000 & 0,000
\end{tabular}

Kelompok intervensi 
Tabel 3 merupakan Efektivitas Aroma Terapi Lavender Untuk Mengurangi Kecemasan Pemasangan IUD Pada Akseptor KB IUD Rumah Bersalin Kasih Ibu Sejati Kota Medan Tahun 2021 pada kelompok intervensi. Dilakukan uji paired sample t test didapatkan hasil untuk $P$ Value $=0,000$ artinya $p<0,05$, menyatakan bahwa Aroma Terapi Lavender Efektiv Untuk Mengurangi Kecemasan Pemasangan IUD Pada Akseptor KB IUD di Rumah Bersalin Kasih Ibu Sejati Kota Medan Tahun 2021.

\section{PEMBAHASAN}

Berdasarkan hasil penelitian mayoritas tingkat kecemasan pada responden pada kelompok control prestest dalam kategori berat yaitu 8 responden (50\%) dan pada saat posttest juga dilakukan pengukuran kecemasan pada kelompok control mayoritas responden juga berada pada kategori kecemasan berat yaitu 11 orang $(42,3 \%)$. Untuk kelompok intervensi mayoritas tingkat kecemasan pada responden pada kelompok intervensi prestest dalam kategori berat yaitu 6 responden $(23,1 \%)$ dam kecemasan sedang 6 responden $(23,1 \%)$ dan pada saat posttest dilakukan pengukuran kecemasan pada kelompok intervensi mayoritas responden juga berada pada kategori kecemasan ringan yaitu 11 orang (42,3\%).

Hasil penelitian ini sejalan dengan penelitian yang dilakukan oleh Dewi Ratna Dila, dkk tahun 2017 dengan judul Pengaruh Aromaterapi Lavender Terhadap Penurunan Kecemasan Ibu Pre operasi section Caesaria di Rumah Bersalin, diberikan kepada 20 responden aromaterapi lavender dan terjadi perbedaan nilai pretest dan posttest dengan uji Wilcoxon rank test didapat nilai pretest kecemasan ibu pre operasi section caserea berat sebanyak 20 (100\%) dan nilai posttest kecemasan ibu ore operasi section caserea sedang sebanyak 20 (100\%) (Dewi Ratna DIla, 2017).

Relaksasi merupakan salah satu bagian dari terapi nonfarmakologi untuk mengatasi atau mengurangi kecemasan serta secara tidak langsung dapat mengurangi nyeri. Relaksasi adalah salah satu cara terapi nonfarmakologis yang digunakan untuk menurunkan intensitas nyeri yang di alami oleh seseorang. Ketika seseorang mengalami gangguan rasa nyeri maka akan meningkatkan saraf simpatis yang menyebabkan ketegangan pada otak dan otot seseorang. Dengan menggunakan teknik relaksasi, maka saraf simpatis akan dihambat, sementara saraf parasimpatis meningkat sehingga mengakibatkan ketegangan otak dan otot seseorang akan berkurang. Banyak jenis relaksasi yang digunakan sebagai terapi nonfarmakologi antara lain relaksasi otot progresif, relaksasi musik,relaksasi aromaterapi dan relaksasi modifikasi (Solehati \& Kosasih,2015).

Aromaterapi berarti pengobatan menggunakan wangi - wangian. Aromaterapi dalam penyembuhan holistik untuk memperbaiki kesehatan dan kenyamanan. Aromaterapi adalah sari aromatik yang disuling dari tanaman, bunga, dan biji. Aromaterapi ini mempunyai kekuatan untuk menyembuhkan dan memperbaiki kesehatan. Semua aromaterapi mempunyai daya menyembuhkan yang unik dan sifatnya yang antiseptik. Beberapa kegunaan aromaterapi antara lain bersifat antivirus, antiperadangan, meredakan rasa nyeri, antidepresan, dan membuat rileks (Sharma, 2009).

Aromaterapi adalah terapi dengan menggunakan berbagai jenis bunga, tumbuhan, minyak wangi, dan wangi-wangian. Holistik aroma menggunakan masase 
dan bau-bauan (Susana \& Hendarsih, 2011). Lavender adalah tanaman semak yang memiliki aroma khusus. Lavender efektif dalam menyeimbangkan sistem saraf dan emosi. Lavender juga digunakan untuk meredakan migran, mengurangi nyeri dan dapat digunakan sebagai antiseptik. Cara : inhalasi , mandi dan masase.

Salah satu cara nonfarmakologi menurunkan tingkat kecemasan pada seseorang saat dilakukan pemasangan IUD yaitu dengan relaksasi. Relaksasi merupakan salah satu bagian dari terapi nonfarmakologis, yaitu Complementery And Alternative Therapies (CATs) yang di kelompokkan dalam Mind-body and spiritual terapies. Terapi relaksasi banyak digunakan dalam menangani nyeri dan kecemasan karena tidak memiliki efek samping, mudah dalam pelaksanaannya, tidak memerlukan waktu yang banyak serta relatif murah. Banyak jenis relaksasi yang digunakan sebagai terapi nonfarmakologis antara lain terapi relaksasi Musik, relaksasi Modifikasi dan relaksasi dengan Aromaterapi (Solehati \& Kosasih, 2015).

Aromaterapi adalah metode yang menggunakan minyak essensial untuk meningkatkan kesehatan fisik, emosi dan spiritual. Efek lainnya adalah menurunkan nyeri dan kecemasan. Minyak essensial atau minyak astiri yang bersifat menurunkan atau menghilangka nyeri salah satunya adalah lavender. (Solehati \& Kosasih, 2015). Lavender ini akan meningkatkan gelombang alfa dalam otak dan gelombang inilah yang akan membuat tubuh menjadi rileks dan akan mengurangi rasa nyeri yang di rasakan (Sharma, 2009).

Aromaterapi juga dapat menurunkan tingkat nyeri pada seseorang yang mengalami kecemasan saat dilakukan pemasangan IUD,sebab aromaterapi juga dapat memberikan efek stimulasi, memberikan sensasi yang menenangkan diri, otak, keseimbangan, stress yang dirasakan, relaksasi pada pikiran dan fisik pada tubuh sehingga efek inilah yang dapat menurunkan nyeri pada seseorang. Jika pikiran terasa tenang dan rileks maka akan tercipta suasana yang nyaman, dan kecemasan pun dapat berkurang (Najmi, 2011).

\section{SIMPULAN DAN SARAN}

\section{SIMPULAN}

Berdasarkan hasil dan pembahasan dalam penelitian Mayoritas tingkat kecemasan pada responden pada kelompok control prestest dalam kategori berat yaitu 8 responden $(50 \%)$ dan pada saat posttest juga dilakukan pengukuran kecemasan pada kelompok control mayoritas responden juga berada pada kategori kecemasan berat yaitu 11 orang (42,3\%). Mayoritas tingkat kecemasan pada responden pada kelompok intervensi prestest dalam kategori berat yaitu 6 responden $(23,1 \%)$ dam kecemasan sedang 6 responden $(23,1 \%)$ dan pada saat posttest dilakukan pengukuran kecemasan pada kelompok intervensi mayoritas responden juga berada pada kategori kecemasan ringan yaitu 11 orang $(42,3 \%)$. Untuk menguji keefektivan aroma terapi lavender dilakukan uji paired sample $t$ test didapatkan hasil untuk $P$ Value $=0,000$ artinya $p<0,05$, menyatakan bahwa Aroma Terapi Lavender Efektiv Untuk Mengurangi Kecemasan Pemasangan IUD Pada Akseptor KB IUD di Rumah Bersalin Kasih Ibu Sejati Kota Medan Tahun 2021

\section{SARAN}

Disarankan kedepannya untuk Pimpinan Rumah Bersalin Kasih Sejati agar bekerjasama dengan tenaga kesehatan dalam memberikan aromaterapi khususnya 
aromaterapi lavender pada ibu yang memiliki tingkat kecemasan pada pemasangan IUD. Disarankan untuk Pimpinan Institusi agar lebih meningkatkan mutu pendidikan dalam proses pembelajaran teori maupun praktik. Agar mahasiswa dapat meningkatkan pengetahuan dan wawasan tentang Aroma Terapi Lavender Efektiv Untuk Mengurangi Kecemasan Pemasangan IUD Pada Akseptor KB IUD. Disarankan kepada peneliti selanjutnya untuk melakukan penelitian sejenis dengan skala penelitian yang lebih luas untuk mendapatkan hasil penelitian yang lebih akurat.

\section{DAFTAR PUSTAKA}

Agustina, Soebacman. 2014. Cetakan 1. Syura Media Utama: Yokyakarta

Azwar, Syaifudin..2015. Sikap Manusia dan Teori Pengukurannya.Edisi 2. Jakarta:Salemba Medika

Dadi Tilong. 2012. Bebas Dari Ancaman Kanker Cerviks, Terbitan ke-1. Jakarta: Salemba Medika

Dila Dewi R. Putra F. Arifin R. Pengaruh Aromaterapi Lavender terhadap Penurunan Kecemasan Ibu Pre Operasi Sectio Caesaria Dirumah Bersalin. Caring Nursing Journal. Vol. 1 No. 2 )Oktober, 2017); ISSN : 2580-0078

Depkes RI. 2010. Kesehatan Reproduksi: Jakarta

Emelia, Ova. 2015. Bebas Ancaman Kanker Cerviks, MedPress Edisi Pertama. Yogyakarta : Salemba Medika

Goldstein J. 2018. Siapa yang Seharusnya Mendapatkan Penggunaan Akseptor KB, diakses 15 Mei 2019. http://blogs.wsi.com/health/2009/11/03/who-should-get-a-papsmearl

Hidayat A. 2015. Metode Penelitian Kebidanan dan Tehnik Analisa data. Edisi Pertama. Jakarta : Salemba Medika

Ikmanun, Luluk. 2015. Hubungan tingkat pengetahuan dan motivasi wanita usia subur dalam melakukan penggunaan KB.diakses 19 Mei 2019

Jaya, Kusnadi. 2018. Keperawatan Jiwa. Pamulang: Binarupa Aksara.

Kurniawati, D, Ninuk. 2016. Asuhan Kebidanan Pada Keluarga Berencana. Jakarta. Salemba Medika.

Kusumadewi dkk. 2013. Informatika Kesehatan, Edisi 1.Yogyakarta. Graha IImu.

Lemeshow S., Hosmer D.W., Klar J., \& Lwanga S.K. 1997.Besar Sampel dalam Penelitian Kesehatan. Yogyakarta: Gadjah Mada University Press.

Lina Mardiana. 2010. : Penggunaan IUD . Jakarta. Penebar Swadaya.

Morrison, R.S., Moody, \& Shelton, Pap Smear: Wanita Usia Subur dan KB, diakses 5 Maret 2019, http://www.rno.org/journal/index.php/online-journal/article/viewfile/236/282

Notoatmodjo S. 2013. Pendidikan dan Prilaku Kesehatan. Rineka Cipta: Jakarta.

Notoatmodjo S. 2007.Promosi Kesehatan dan Ilmu Perilaku. Jakarta. Rineka Cipta.

Rahmitha, Nurul. 2017. Tingkat Kecemasan pada Ibu Infertil.

Riyanto, Agus. 2018. Aplikasi Metodologi Penelitian Kesehatan Dilengkapi Contoh Kuesioner dan Laporan Penelitian.Yogyakarta: Nuha Medika 